\title{
IMPEDANCE MONITORING OF BACTERIAL ACTIVITY
}

\author{
A. UR* AND D. F. J. BRowN $\dagger$ \\ Divisions of Bioengineering* and of Hospital Infection $\dagger$, Clinical Research Centre, \\ Harrow, Middlesex, HA1 $3 U \mathrm{~J}$
}

RoUTINE microbiology has not kept pace with the advances towards rapid and automated methods that have occurred in clinical chemistry and in haematology. The long incubation periods necessary for the growth of bacteria both in isolation procedures and in specific secondary tests, such as antibioticsensitivity and biochemical tests, make the time saved by automation insignificant. Automation and speeding up of microbiological tests would therefore benefit from sensitive methods based on features observable at very low concentrations of organisms. Ur $(1970 a)$ suggested that changes in the electrical impedance of a growing bacterial culture might be monitored to detect activity of organisms, the probable advantages of the approach being the high sensitivity offered by detection of minute impedance changes and the relative simplicity of the apparatus needed. We report the development of such a system (see also Ur and Brown, 1973) and some of its potential applications in microbiology. The method is based on the continuous comparison of changes in the electrical impedance of a growing culture with changes in the impedance of a control sample of sterile broth. The method, previously used for detection of other reactions, such as blood coagulation (Ur, 1970a and $b$ ), isolates the signal caused by the activity of the micro-organisms by cancelling a major part of the "noise" and "drift" from other processes, such as temperature fluctuation, evaporation of water, enzymatic reactions in the medium and accidental contamination, which are common to test and control sample. The apparatus may provide the basis for rapid automated systems in routine microbiology as well as providing results of theoretical interest.

\section{MATERIALS AND METHODS}

Bacterial strains. These were strains of Staphylococcus aureus (including the " Oxford $\mathrm{H}$ " strain no. NCTC6571), Escherichia coli, Klebsiella aerogenes, Pseudomonas aeruginosa, and Streptococcus faecalis. Inocula were prepared by emulsifying several colonies from an overnight blood-agar culture in the experimental medium and diluting the suspension in the same medium to provide the inoculum required. Viable counts of bacteria were made by the technique of Miles, Misra and Irwin (1938).

Media. Peptone Water (Oxoid CM 9), Tryptose-phosphate Broth (Difco no. 0060), Nutrient Broth (Oxoid CM 1), and PPLO Broth (Difco no. 0554) were prepared as directed by the makers. Glucose broth was prepared by adding sterile glucose solution to nutrient broth to a final concentration of $1 \%$. Supplemented PPLO broth was prepared by adding $10 \mathrm{ml}$ of $25 \%$ yeast extract, $20 \mathrm{ml}$ of horse serum, $2 \mathrm{ml}$ of $0.1 \%$ phenol red, and $1 \mathrm{ml}$ of $10 \%$ arginine to $70 \mathrm{ml}$ of PPLO broth. The $p \mathrm{H}$ was then adjusted to 7.0 with $\mathrm{N} \mathrm{HCl}$. All the media except the PPLO broths are commonly used in bacteriology. 
Impedance measurement. The changes in the electrical impedance of the bacterial cultures were monitored at $10 \mathrm{KHz}$ sinusoid alternating current by the use of matched pairs of conductivity measuring cells (Stratton \& Co. Medical Ltd, UK) having their orifices closed with plastic plugs (fig. 1). The cells are made of precision glass capillary of 2-mm internal diameter with gold electrodes plated on the inside and outside of the capillaries at each end. After sterilisation in a hot-air oven at $100^{\circ} \mathrm{C}$ for $3 \mathrm{~h}$, the test and reference cells were filled respectively with the suspension and sterile control medium by means of 25 -gauge hypodermic needles inserted through the plastic plugs. The tubes were then sealed with petroleum jelly.

Each pair of cells was placed in the cell-holder of the measuring instrument (Stratton \& Co. Medical Ltd; patents held or pending in many countries). They were in a slightly slanted position so that any bubbles accidentally trapped in them floated to one end and did not affect the impedance measurement. The two cells formed part of a measuring-bridge circuit previously described (Ur, 1970a and $b$ ). The bridge was offset by a predetermined value to ensure that the expected impedance changes were on one side of the bridge balance-point. The output signal from the bridge, which relates to the impedance changes, was recorded on a chart recorder. Experiments in which both cells contained sterile broth served as a control.

The absolute resistance of the test and control cells was measured at the beginning and at the end of the experiments by balancing the bridge and substituting each cell in turn by a calibrated resistor box. Technical details of the apparatus are described elsewhere (Ur and Brown, 1974).

After completion of the experiments, the contents of the cells were inoculated on to blood agar and incubated overnight at $37^{\circ} \mathrm{C}$ to check the purity of the cultures and the sterility of the controls.

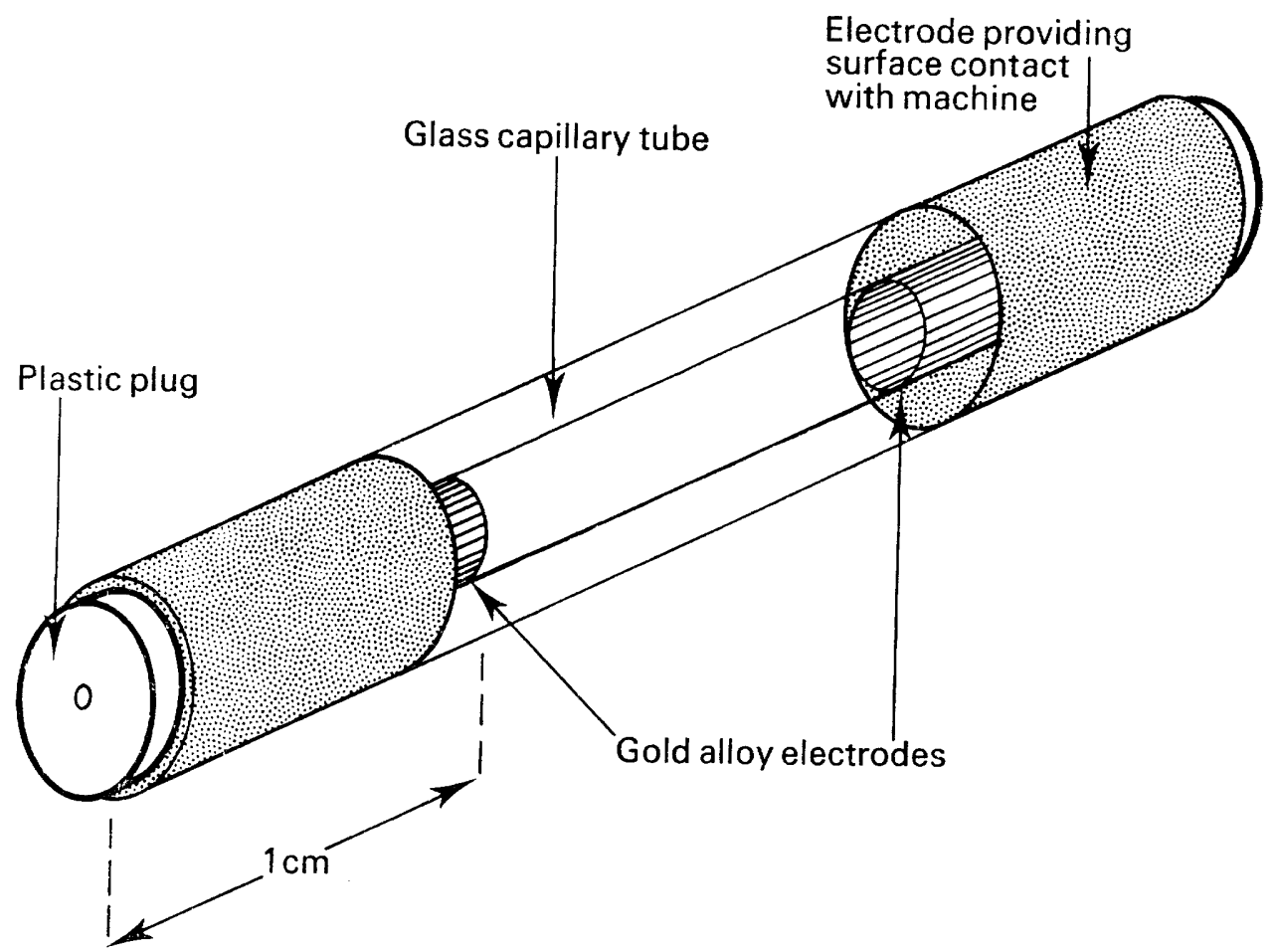

FIG. 1.-The comparative impedance monitoring cell. 
Sterile antibiotic solutions. These were freshly prepared in distilled water and diluted in the experimental medium to the required concentration. The medium containing antibiotic was inoculated with bacteria as described above, except that it was used for the final dilution only.

The buffering capacity of the media. This was estimated by adding $0 \cdot 1 \mathrm{~N} \mathrm{HCl}$ to $15 \mathrm{ml}$ medium and measuring the change in $p \mathrm{H}$ with a Pye Unicam Model-291 pH meter. The buffering capacity of glucose broth was not determined.

\section{RESULTS}

Impedance curves during the growth of Escherichia coli in PPLO broth

The impedance changes associated with the growth of a culture of $E$. coli in PPLO broth are shown in fig. 2, together with a growth curve constructed from the mean of duplicate viable counts on cultures in measuring cells similar to those used for the impedance measurement. The main features of the curves and the duration of the lag and logarithmic phases of growth are similar. Although invariably the growth of the culture was associated with a drop in impedance of about $5 \%$, the impedance of the control cells varied by less than $0.5 \%$, which represented drift caused mainly by minute amounts of evaporation. This evaporation affected both cells, and the effect of drift was therefore largely cancelled. At the end of the experiment, the cell containing bacteria

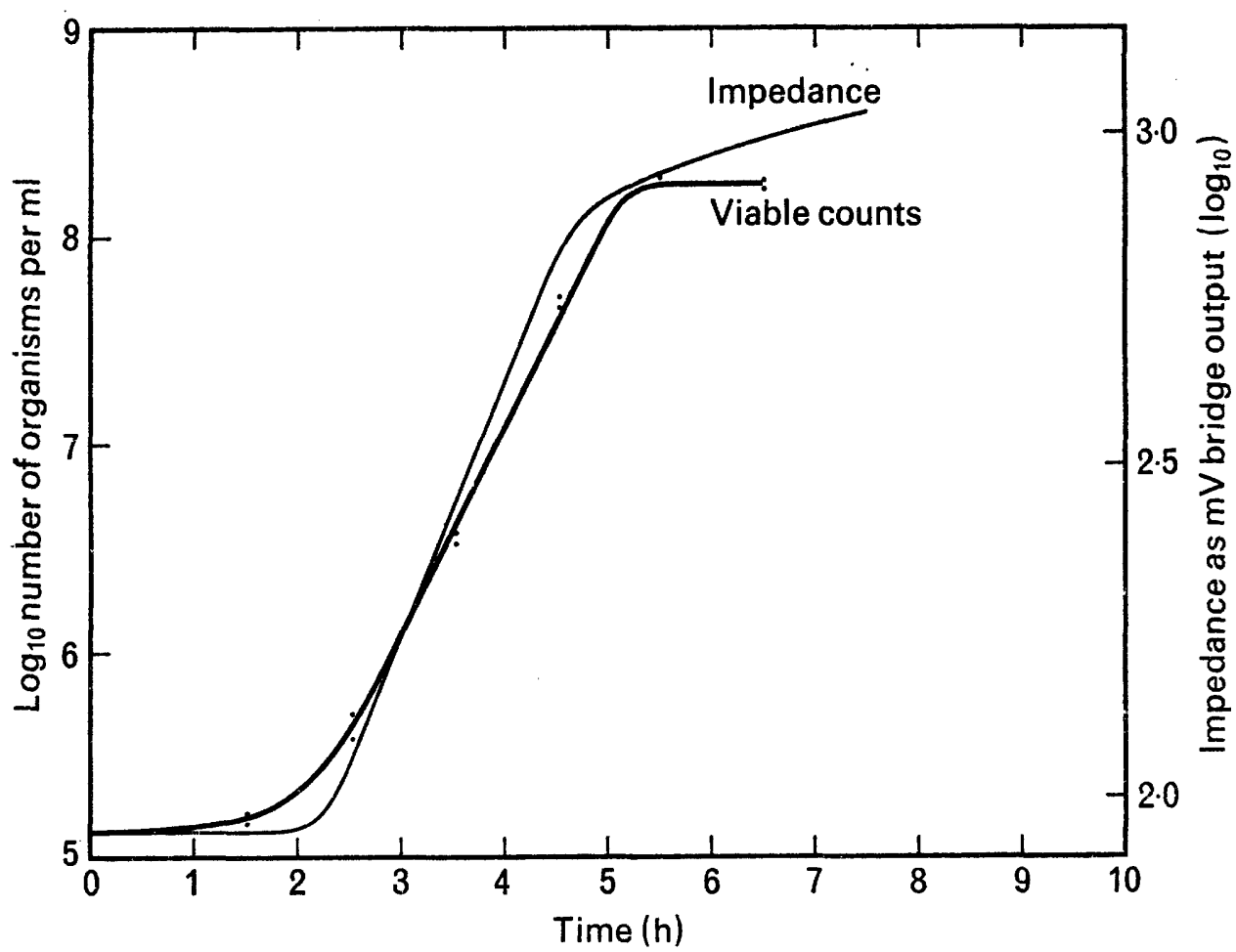

FIG. 2.-Curves of changes in comparative impedance and of number of viable organisms in a culture of Escherichia coli growing in PPLO broth. 
was rotated to check the possible effect of sedimentation. This did not significantly affect the impedance value of the cells, and the signal, monitored for another $5 \mathrm{~h}$, remained constant.

\section{Impedance curves during the early stages of incubation of different bacteria}

The inoculum in this series of experiments was $10^{5}$ organisms per $\mathrm{ml}$. For most tests it was unnecessary to plot the entire impedance curve, so greater amplification of the signal could be used to allow closer analysis of the early parts of the curve. In fig. 3, the activity of $E$. coli is obvious in less than $1 \mathrm{~h}$ when an amplified, non-logarithmic scale is used; this contrasts with the $2 \mathrm{~h}$ required in fig. 2 , where the amplification is much less and the scale logarithmic. Similar curves were observed with other organisms, as shown in fig. 3 , but the speed and magnitude of response varied. With $P$. aeruginosa, the only obligate aerobe included in this experiment, the response was much slower than with other organisms.

\section{The influence of medium}

Experiments with various media gave curves of similar shape but which differed in amplitude and in the duration of phases of the curve. Fig. 4 shows impedance curves of the Oxford staphylococcus grown in different

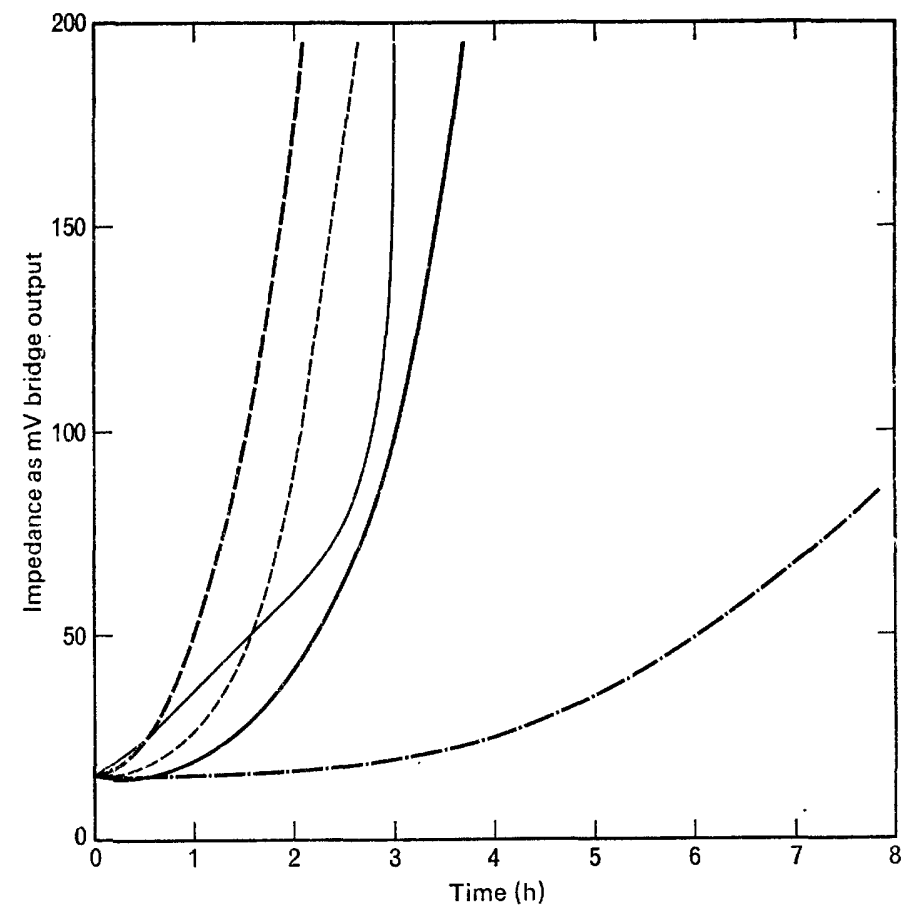

FIG. 3.-Comparative impedance curves of different organisms grown in PPLO broth: Escherichia coli, _- - ; Klebsiella aerogenes, - - ; Staphylococcus aureus, _-; Streptococcus faecalis, —- 
media. The inoculum was $10^{4}$ cells per $\mathrm{ml}$. The major difference between the curves with different media was seen in the initial time-lag before the curve began to rise rapidly. With PPLO broth this was $2 \mathrm{~h}$, but it required $3 \frac{1}{2}, 4$, $4 \frac{1}{2}$ and $5 \mathrm{~h}$ respectively with supplemented PPLO broth, nutrient broth, peptone water, and tryptose-phosphate broth.

Differences in the buffering capacity of the different media (the table) were thought to provide a reason for differences in the length of the initial lag period. Tryptose-phosphate broth showed the greatest buffering effect. Other media showed less buffering capacity in the order: supplemented PPLO broth, PPLO broth, nutrient broth, and peptone water.

\section{The effect of inoculum size}

With each organism in each medium the rate of response was proportional to the size of the inoculum. An example of the effect of inoculum on the early

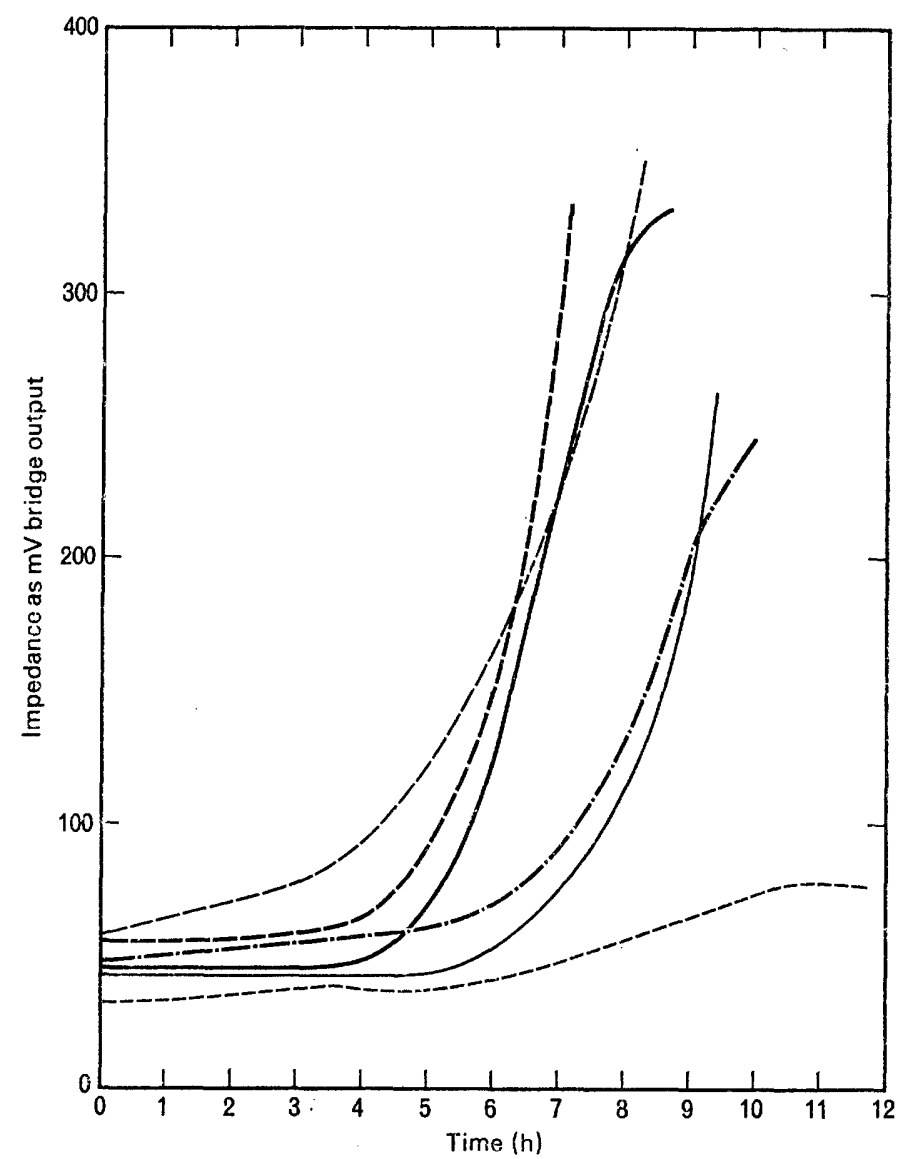

Fig. 4.-Comparative impedance curves of the Oxford staphylococcus grown in different media: PPLO broth, - - - ; supplemented PPLO broth, - - - ; nutrient broth, - ; peptone water, - - - . ; tryptose-phosphate broth, ㄴ. 
TABLE

The buffering capacity of different media compared by measuring the change in $\mathrm{pH}$ on addition of hydrochloric acid

\begin{tabular}{|c|c|c|c|c|c|}
\hline \multirow{2}{*}{ Medium } & \multirow{2}{*}{$\begin{array}{l}\text { Initial } \\
\mathrm{pH}\end{array}$} & \multicolumn{4}{|c|}{$\begin{array}{l}\text { Change in } p H \text { after addition of } \\
\text { volumes of hydrochloric acid* }(\mathrm{ml})\end{array}$} \\
\hline & & 0.1 & 0.2 & 0.3 & 0.4 \\
\hline $\begin{array}{l}\text { Peptone water } \\
\text { Nutrient broth } \\
\text { Tryptose-phosphate broth } \\
\text { PPLO broth } \\
\text { Supplemented PPLO broth }\end{array}$ & $\begin{array}{l}7 \cdot 2 \\
7 \cdot 2 \\
7 \cdot 3 \\
7 \cdot 78 \\
7 \cdot 04\end{array}$ & $\begin{array}{l}0 \cdot 10 \\
0 \cdot 10 \\
0.05 \\
0.01 \\
0.07\end{array}$ & $\begin{array}{l}0 \cdot 20 \\
0 \cdot 20 \\
0 \cdot 10 \\
0 \cdot 18 \\
0 \cdot 14\end{array}$ & $\begin{array}{l}0.40 \\
0.30 \\
0 \cdot 10 \\
0.30 \\
0.33\end{array}$ & $\begin{array}{l}0.50 \\
0.45 \\
0.10 \\
0.43 \\
0.29\end{array}$ \\
\hline
\end{tabular}

$* 0 \cdot 1 \mathrm{~N} \mathrm{HCl}$ added to $15 \mathrm{ml}$ of medium.

part of impedance curves of $E$. coli in PPLO broth is shown in fig. 5. Within the range of inocula covered in this experiment a 10-fold increase in the inoculum size reduced the response time by $1 \mathrm{~h}$.

\section{The effect of antibiotics}

When antibiotics were included in the media a delaying effect on the change in impedance was apparent within $2-2 \frac{1}{2} \mathrm{~h}$. Fig. 6 shows the inhibitory effect of tetracycline, ampicillin, and kanamycin on a sensitive strain of $E$. coli. The media used all contained antagonists of sulphonamide activity (Harper and Cawston, 1945) and response to this drug was not evident, unlike the

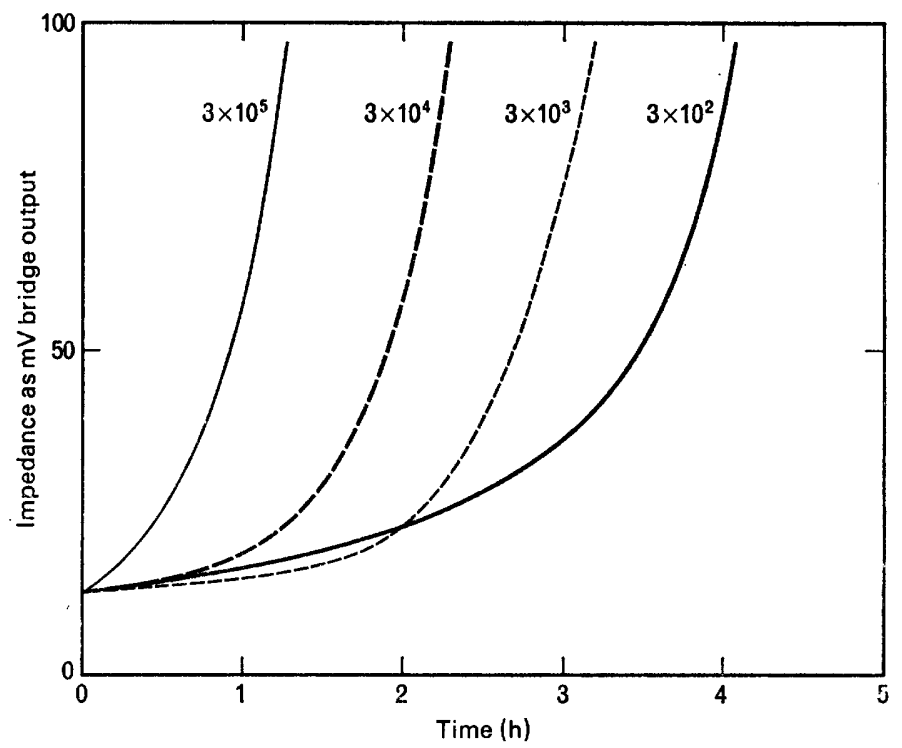

FIG. 5.-The effect of inoculum size on impedance growth curves of Escherichia coli grown in PPLO broth. The initial number of organisms per $\mathrm{ml}$ medium is shown at the upper end of each curve. 
findings with other antibiotics. Any strain resistant to the antibiotic tested gave a curve similar to that in drug-free medium.

\section{Discussion}

The curve of impedance changes indicates an effect accumulative with time. Such an effect might be expected as the products of metabolism accumulate in a growing culture. Thus, for example, when the culture reaches the stationary phase, the impedance curve continues to rise linearly (on a non-logarithmic scale), representing the continued metabolism of the stationary or slowly growing culture (fig. 2).

The impedance always decreased with time, indicating that the microorganisms metabolised substrates of low electrical conductivity, such as carbohydrates, into products of higher conductivity, such as lactic acid. The increased conductivity is caused by an increase in the number of molecules migrating in the electrical field, their smaller size, increased electrical charge, or a combination of such causes. It is also possible that the curve is a summation of several processes, some of which may be antagonistic.

The mechanisms underlying the formation of such curves were revealed to some extent by comparing the impedance curves from different media

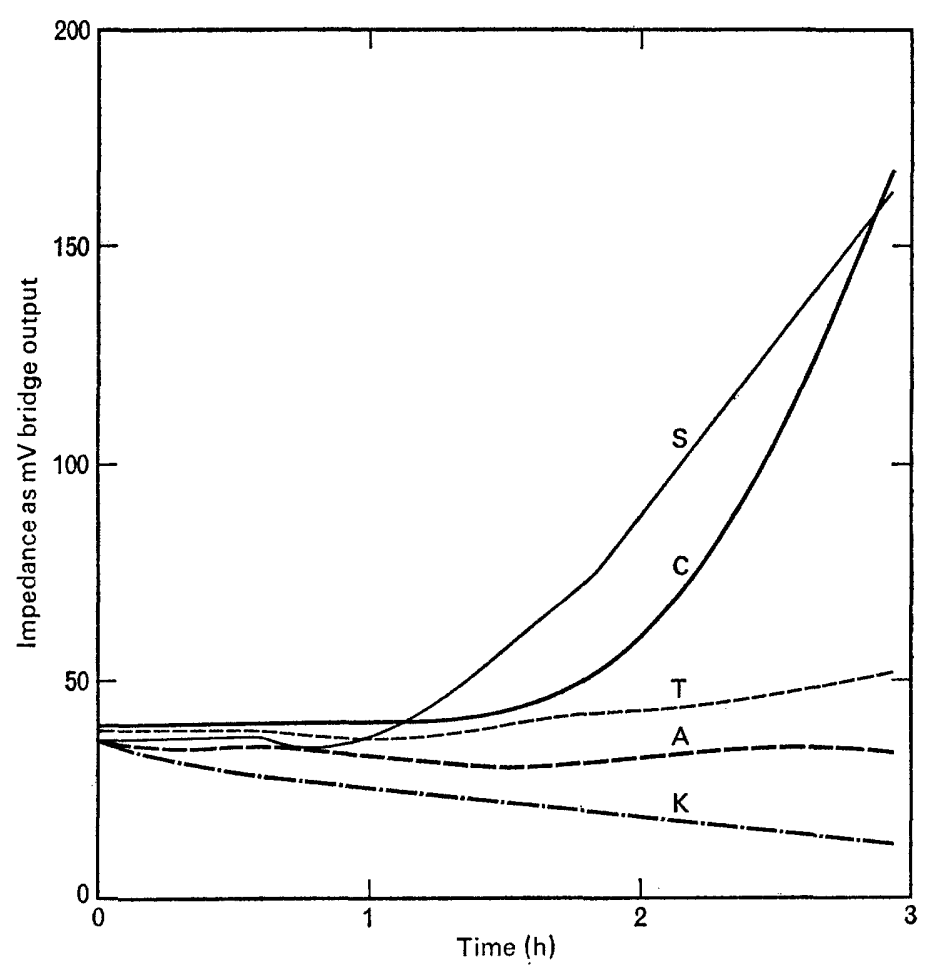

FIG. 6.-The effect of antibiotics on impedance growth curves of a sensitive strain of Escherichia coli: $\mathrm{C}=$ antibiotic-free control; $\mathrm{S}=$ sulphonamide $200 \mu \mathrm{g}$ per ml; $\mathrm{T}=$ tetracycline $10 \mu \mathrm{g}$ per $\mathrm{ml} ; \mathrm{A}=$ ampicillin $10 \mu \mathrm{g}$ per $\mathrm{ml}$; and $\mathrm{K}=$ kanamycin $10 \mu \mathrm{g}$ per $\mathrm{ml}$. 
(fig. 4). It was obvious that with some media, such as tryptose-phosphate broth, the impedance did not change appreciably for a period exceeding the bacterial lag phase. The length of the impedance lag period was inversely proportional to the size of the inoculum (fig. 5), suggesting that a change in impedance occurred only after sufficient metabolites had accumulated to overcome a barrier. The strength of this barrier varied with different media, and the results of titration of the media against hydrochloric acid indicate some relationship between buffering capacity and length of lag; tryptose-phosphate broth has the greatest buffering capacity and indeed showed the longest lag. Media with similar buffering properties sometimes showed different lag periods because of differences in nutritional properties. For example PPLO broth showed a greater signal during the lag phase (fig. 4) and has less buffering capacity than the supplemented medium. However, the supplemented medium is considerably more nutritious and once the lag ended the signal increased much more rapidly than with PPLO broth. The correlation between the length of initial lag period and the buffering capacity of the medium shows that a dominant part of the curve is caused by the same mechanism that causes $p \mathrm{H}$ changes.

The low level of response in glucose broth is puzzling. The added carbohydrate should cause a more rapid change in $p \mathrm{H}$ than with nutrient broth, so a more rapid impedance change was expected. The observation was not investigated further, because other media were considered more suitable for further experiments at the time, and this unexpected response remains to be elucidated.

Experiments with completely defined media may explain the exact mechanism responsible for the changes in impedance and perhaps enable preparation of media showing a shorter lag or greater response during the lag, these being the desirable features of this method in bacteriology. PPLO broth, a complex medium containing infusion from beef heart, peptone, and sodium chloride, has so far proved to be the most satisfactory medium. The rate of response with PPLO broth varied with the organism and inoculum size, but with inocula of $10^{5}$ activity was detectable with all organisms within $1 \mathrm{~h}$. Modification of media according to known biochemical reactions, specific for the microorganism concerned, may lower the threshold related to bacterial concentration and provide a greater response rate. The impedance method provides a sensitive and rapid means of detecting, and, under standardised conditions, measuring the activity of micro-organisms. Curves can be closely correlated with growth curves of viable organisms (fig. 2) and readings are recorded automatically and continuously. Furthermore, a signal can be detected immediately with concentrations of bacteria as low as $10^{4}$ per $\mathrm{ml}$ in a culture volume of only $0.1 \mathrm{ml}$. The rate of response showed close correlation with the concentration of bacteria in the initial inoculum for each strain tested so correlation curves could be constructed to estimate the number of viable cells in a suspension.

In diagnostic microbiology the method could perhaps be applied to the rapid identification of micro-organisms. Different organisms in the same medium gave different impedance growth curves and the same organism in different 
media gave different curves. Media might possibly be prepared for tests according to known biochemical reactions, and specific growth inhibitors or promoters could be added. A combination of such tests would allow rapid identification of unknown micro-organisms. The demonstration within a few hours of antibiotic effect on bacteria points to the potential use of this method in rapid antibiotic-sensitivity tests. The effect of antibiotics on the impedance growth curve is recorded quantitatively, so the method may provide a rapid means of performing assays of antibiotics in serum.

Another possible use in diagnostic bacteriology is the detection of slowly growing pathogens such as Mycobacterium and Mycoplasma. Experience with Mycoplasma argininii showed the activity of the organisms to be detectable within $3 \mathrm{~h}$ with inocula of $10^{5}$ organisms per $\mathrm{ml}$. As the activity of bacteria, and not simply increase in their numbers, is measured, it may even be possible to detect microbial activity in the absence of cell division, for example, with slowly growing organisms or in the presence of bacteristatic drugs.

\section{SUMMARY}

Bacterial activity and growth were monitored by following the changes of electrical impedance of cultures in liquid media. The signal is expressed automatically as a curve similar to growth curves produced by other methods. The technique offers a new, rapid and sensitive means of detecting active microorganisms and is potentially the basis of rapid automated systems in this field. The impedance changes indicate that the micro-organisms metabolise substrates of low conductivity into products of high conductivity and that the changes are due to the activity of the micro-organisms rather than increase in their numbers.

The activity of strains of Escherichia coli, Klebsiella aerogenes, Pseudomonas aeruginosa, Staphylococcus aureus, and Streptococcus faecalis was detected within $2 \mathrm{~h}$ with inocula of $10^{3}-10^{5}$ organisms per $\mathrm{ml}$. Different reactions of bacteria in various media suggest that the method may be applied to the rapid identification of micro-organisms. The inhibitory effect of antibiotics on bacteria was demonstrated within $2 \mathrm{~h}$, indicating that the method may be useful for the rapid determination of bacterial sensitivity to antibiotics and the rapid assay of antibiotics in serum. Correlation of response time to initial inoculum allows estimation of numbers of viable organisms. The sensitivity of the method allowed detection of activity due to Mycoplasma argininii within $3 \mathrm{~h}$; this suggests that the method might be applicable to the rapid detection of other slowly growing organisms, such as mycobacteria.

We thank Mr Michael Gordon for valuable discussion, Mr David Norman for construction of the instruments, Mr Devendra Kothari for assistance with the bacteriological work, $\mathrm{Mr} \mathrm{A}$. E. Lowe for designing the accurate temperature-control systems, and $\mathrm{Mr}$ Paul Darton for the illustrations.

D. B. is a member of the staff of the Central Public Health Laboratory, seconded to the Clinical Research Centre. 


\section{REFERENCES}

HARPER, G. J. AND CAWSTON, W. C. 1945. The in vitro determination of the sulphonamide sensitivity of bacteria. J. Path. Bact., 57, 59.

Miles, A. A., MisRA, S. S. AND IRwIN, J. O. 1938. The estimation of the bactericidal power of the blood. J. Hyg., Camb., 38, 732.

UR, A. (1970a). Determination of blood coagulation using electrical impedance measurements. Bio-med. Engng, 5, 342.

UR, A. 1970b. Changes in the electrical impedance of blood during coagulation. Nature, Lond., 226, 269.

UR, A. AND Brown, D. F. J. 1973. Detection of bacterial growth and antibiotic sensitivity by monitoring changes in electrical impedance. Int. Res. Commun. System-J. int. Res. Commun., 1, (6), 37.

UR, A. AND BROWN, D. F. J. 1974. Rapid detection of bacterial activity using impedance measurements. Bio-med. Engng, 9, 18. 